\title{
TECHNICAL ANALYSIS AND ITS THEORETICAL BASIS FOR TRADING ACTIVITY MANAGEMENT
}

\author{
Maria Lyakina ${ }^{1, \mathrm{a},{ }^{*}, \text { Blagovesta Koyundzhiyska-Davidkova }}{ }^{2, \mathrm{~b}}$ and Jozsef Popp ${ }^{3, \mathrm{c}}$ \\ ${ }^{1}$ Emperor Alexander I St. Petersburg State Transport University, Faculty of Economics \& \\ Managment, Department of Transport Economics. 9, Moscovskiy pr., Saint-Petersburg, \\ Russia, 190031 \\ ${ }^{2}$ South-West University, Department of Economics, 2700 Blagoevgrad, Bulgaria \\ ${ }^{3}$ John von Neumann University, Hungarian National Bank - Research Center, 6000 \\ Kecskemét, Hungary; Izsáki út 10., Department of Public Management and Governance, \\ College of Business and Economics, University of Johannesburg, Johannesburg 2006, South \\ Africa \\ amalyakina@mail.ru, bvesi_8808@abv.bg, ${ }^{a}$ popp.jozsef@uni-neumann.hu \\ ${ }^{*}$ Corresponding author
}

Cite as: Lyakina, M., Koyundzhiyska-Davidkova, B., Popp, J. (2021). Technical analysis and its theoretical basis for trading activity management, Ekonomicko-manazerske spektrum, 15(2), 52-64.

Available at: dx.doi.org/10.26552/ems.2021.2.52-64

Received: 24 August 2021; Received in revised form: 19 October 2021; Accepted: 31 October 2021; Available online: 30 December 2021

\begin{abstract}
:
Research background: In today's era of modern technology, traditional and new methods as well as processes and technologies increasingly contrast. In the first chapter, we focused on a detailed description of the first historical changes in the emergence of trade and financial derivatives. We also identified and described the emergence of specialised trading and stock exchange locations. We continued with a description of the basic methods of analysis and focused on the basics of technical analysis. In the next chapter, we evaluated the current state of research in this area and, based on previous research, we classified and structured individual studies.

Purpose of the article: The aim of our contribution is to examine, in detail, the basics and current research in the field of technical analysis.

Methods: We consider the inconsistent results of the studies analysed to be very interesting. We consider the unsystematic and inconsistent methodology of the assessment of individual studies to be a major problem. As we mentioned in the article, in many instances the studies analysed focused only on individual aspects of technical analysis and evaluated the final results of the business process.

Findings \& Value added: In other cases, the results were skewed, mainly due to the nonacceptance of transaction costs or due to risk abstraction. However, despite such results, technical analysis as such can be a valuable tool for predicting price movements. Subsequently, we described our findings, interpreted them, and identified their limitations. We consider the aim of the study to have been met, and believe that it will be beneficial in the field of research on this issue.
\end{abstract}

Keywords: financial markets, technical analysis, prediction

JEL Classification: G10, G15, G17 


\section{Introduction}

'History is truly a teacher of life: it teaches us that it is a shame that, despite its teachings, people always make the same mistakes'.

Ugo Bernasconi Italian painter and writer 1874 - 1960

In a detailed study of the literature, scientific papers, and financial market issues, we are likely to identify many definitions of the financial market. In her publication, 'Financial Markets Analysis', Hrvolova (2001) cites the most economical and used definition by the American economist, Mishkin, who defines the financial market as follows:

'The financial market is a system of economic instruments, institutions and relationships that brings together, distributes, and redistributes funds among economic operators on the basis of supply and demand'.

As such, we often define the financial market according to its characteristics, functions, and activities. One of the most important features of the financial market is the ability to create conditions for meeting supply and demand. The financial market creates a suitable environment that allows the interaction between the supply and demand of financial instruments, which are cash, securities, pre-emptive rights, and numerous financial market derivatives.

In today's world, in which financial markets are characteristic and very often associated with advanced mathematical indicators, state-of-the-art computing, sophisticated analytical tools, many different predictions and methods, and many new modern expressions, we can gain the false belief that financial markets are an attribute of modern society. While it is true that financial markets have undergone very significant developments in recent decades, especially in the implementation of IT technologies, their roots date back to the distant past.

Therefore, we consider a brief historical overview of the development of trade and financial markets to be highly beneficial for the processing of theoretical data, which will help us to penetrate deeper into this very complex issue using specific historical examples.

\subsection{Overview of financial market history}

In an effort to find the first documented signs of progress in trade as a peculiar, and above all, independent economic activity, we identified that the first formalised principles of trade existed in the ancient Babylonian Empire, according to available historical sources. An example of such principles is Section 48 of the Chammurappi Code (ca. 4000 BC), which states that in the event of a crop failure, when farmers incur losses, the persons who incur those losses (not only farmers) are exempted for one year from the payment of interest (in the form of grain). Stupavsky (2007) states, in his publication, 'It started with grain and ended with the weather', that this is probably one of the first documented mentions of options ever.

Another very interesting example of trade progress and an historically documented example of derivative trading can be found in Chapter 29 of Genesis. This is an agreement between Jacob and Laban (1700 BC). This particular example is also mentioned by Don. M. Chance (1998) in his well-known treatise, 'Essay in Derivates'; the author identifies it as an option contract, but notes that it could also be a forward.

We consider it extremely important that, with the gradual development of human society, the motivations and ways that led to the conclusion of various new types of contracts and trades developed. Very interesting is the example of the early contract of the philosopher, Thales of Miletus (624 BC $-548 \mathrm{BC}$ ), which aimed to prove the claim that it was easy to 
become rich through the use of reason and knowledge. The essence of his business was that, based on his own knowledge and expertise in the field of astronomy, he predicted the upcoming very rich olive harvest. Based on this prediction, he therefore purchased an option contract for the lease of olive oil presses. According to his expectations, his prediction came true, and his investment realised a profit.

Trade, as a special and self-separate economic activity, began to emerge in our territory after the separation of crafts from agriculture and at the interface of the ancestral and slave societies. Furthermore, in his publication, 'History of Trade', the author claims that the beginnings of feudalism have caused a big step backwards in the field of trade, which we can do in 5-8. century to identify as a decline in trade across Europe.

We also consider the emergence of securities to be a very important milestone in the history of trade and financial markets. For the first time in history, securities were identified in ancient times and have Hellenic origins. As an example, we can cite the Alexandrian period, when a banker issued a written confirmation of a deposit to the depositor and the borrower, thus confirming his obligation by issuing a signed debt note. The more complex development of securities continues in the middle ages. At this time, the so-called general interest certificates emerged. These interest certificates were used and issued mainly by highranking people of the time, such as the pope, kings, and feudal officials. The essence of such general interest certificates was to publicly acknowledge own debt and to oblige its debtors to repay such a loan with appropriate interest. (Hrvolova, 2001)

Further developments in securities continued in the early Middle Ages with the emergence of bills of exchange in northern Italian urban centres, aimed at making cashless payments, and the emergence of the first stocks dating back to 1188. The creation and existence of joint stock companies enabled the financing of seafaring and the discovery of new sea routes to distant overseas countries. (Hrvolova, 2001)

A very significant milestone in the history of trade is the fact that, simultaneously with the development of trade as an independent economic activity, specialised places began to form and develop, directly intended for the implementation of these trades. The first mention of the origin of such places can be traced back to the 12th and 13th centuries. (Vesela, 2007)

Pavlat (2003), in his publication, 'Stock Exchange', describes in detail that the origin of the name, 'Stock Exchange', is derived from a well-known banker from the 16th century named Van der Buerse. In front of this family's family home in Bruges, buyers from all over Italy began to gather and trade regularly. The origin of the first official stock exchange dates back to 1608, when the Amsterdam Stock Exchange was established and thus became the first stock exchange on which equity securities were traded. (Musilek, 2011)

In his publication, 'Investment Bubbles in Amsterdam', Bascin (2007) further adds that Amsterdam became a respected city of trade in the seventeenth century, in which up to two thirds of goods coming into world trade were transhipped. Daily, from 1,000 to 8,000 ships from all over the world were located and moored in this port. The great advantage of the Amsterdam Stock Exchange over its predecessors was that it had a warehouse in which all incoming goods were stored.

Bascin's publication continues that the old Amsterdam Stock Exchange dates back to 1530, and the new building to 1631. The Amsterdam Stock Exchange was initially focused strictly on commodity trading; however, over time, and with the emerging need to trade with other financial instruments, the stock exchange soon became a place where securities also appeared. Although it is true that securities trading took place even before the Amsterdam Stock Exchange, it never reached such dizzying volumes at the time. At its peak, the Amsterdam Stock Exchange became a place of free trade in the shares of large and small 
companies, government bonds, and bills of exchange. An important fact was that the stock exchange actively cooperated with banks, which helped to facilitate rapid, reliable, and efficient settlement of trades.

This was followed by stock exchanges in other centres of the world at the time, such as Paris, London, Hamburg, and Berlin. The establishment of the first stock exchange in Japan, in the city of Osaka in approximately 1650, is very important for the further development of trading, specifically for the development of prediction methods.

We can consider the breakthrough of the 18th and 19th centuries, when stock exchanges developed on the North American continent, to be a breakthrough in financial markets and stock exchanges. Subsequently, the secondary organised market in New York and the two largest derivatives exchanges in the world officially emerged in 1792, the Chicago Board of Trade (CBOT) in 1848, and the Chicago Mercantile Exchange (CME) in 1874 (Musilek, 2011). Along with the development of stock exchanges, financial markets, and the emergence of new financial instruments, methods are also being developed to help traders and investors predict the price movements of various financial instruments. Douglas (2010) points out three basic directions in which prediction methods can be included, namely, fundamental, technical, and psychological or mental analyses.

Fundamental analysis focuses on estimating the intrinsic value of securities, such as bonds and stocks, for which it uses various economic factors. An investor or trader uses fundamental analysis and intrinsic securities data as a tool to search for undervalued or overvalued securities, and can subsequently generate a profit based on this information. The most basic essence of fundamental analysis is explained by the following statements:

'The value of a stock is primarily affected by dividend estimates and expectations and future interest rate developments'. (Kohout, 1998)

'The most basic fundamental measure for a stock's valuation is the price / earnings ratio $(P / E)$. The share measure determines the ratio of the market price of a share to the annual earnings per share'. (Siegel, 2011)

Traders and investors tend to apply fundamental analysis procedures in two directions, from top to bottom or from bottom to top. The most commonly used approach, especially for bonds, is top-down analysis, which is one in which an investor first analyses global trends in the world economy, continues with an analysis of the region and sector, until they reach an analysis of a particular financial instrument. If the investor chooses the opposite procedure, namely the bottom-up procedure (used especially in the case of stock titles), they will proceed in the exact opposite direction. As already mentioned, fundamental analysis is based on estimates of the intrinsic values of securities based on economic factors, while technical analysis is characterised by the analysis of historical data, such as prices and trading volume (Chavarnakul and Enke, 2009; Teixeira and Oliveira, 2010). We can consider the essence of Graham's work, which he published in his famous book, 'Intelligent Investor', as the basis of modern fundamental analysis. The basic rules of fundamental analysis that Graham thus established were further evaluated by authors such as Oppenheimer and Schlarbaum (1981), but also by Metghalchi, Chang, and Marcucci (2008). Based on their own application of Graham's foundations, they concluded that higher returns could actually be achieved compared to a buy-and-hold strategy.

Another type of analysis that we use is the so-called psychological or mental analysis. This type of analysis entails examining the human psyche and its impact on all aspects of trafficking. It seeks to identify individual patterns of behaviour in the market. These patterns of behaviour are based on the basic emotions perceived by individual traders. This type of analysis identifies three basic emotions that fundamentally influence the direction of the 
market: fear, greed, and hope. If a trader successfully identifies one of these emotional patterns of behaviour in the market, it can greatly help them to effectively predict future prices.

The last mentioned direction in the field of analysis of financial instruments and prediction of their future price movements is technical analysis. This type of analysis has existed since the days of organised markets. According to Douglas (2010), it was not accepted as a useful tool until the turn of the 70's and 80's. The shift from fundamental analysis to the adoption of the basic techniques of technical analysis did not occur until the market community had stopped ignoring its underlying fundamentals. A specific number of market participants participate in market trading on a given day, week, or month. Many of them repeat the same or very similar business steps in an effort to collect revenue. In other words, certain specific patterns of behaviour are developed for individual traders, and groups of these market participants, which interact regularly and create collective patterns of behaviour. Technical analysis seeks to identify and measure these patterns. As a method of predicting price movements, it organises collective behaviour into identifiable patterns, from which it is often possible to assume an increased probability of a certain scenario. For a detailed understanding and description, we will deal with technical analysis later in the dissertation in a separate chapter.

The first major academic study that chose technical analysis as its research topic was, ' $\mathrm{Can}$ Stock Market Forecasters Forecast?'. The author was Alfred Cowles III., who published it in July 1933 in the periodical, 'Econometrica'. The purpose of this study was to verify whether 45 selected professional subjects could effectively predict future stock market movements. (Cowles, 1933)

Northcott (2009) adds that Munehisa Homma was one of the first to use the concepts of technical analysis in the rice market in Japan in the 17th century. These techniques are currently known as the 'candlestick pattern'.

Turek (2011), in his book, 'Manual of Technical Analysis', claims that the Japanese used technical analysis for their own needs of commodity trading, but mostly rice, as early as the 17th century. However, he adds and clarifies that the type of technical analysis used by traders in 17th-century Japan differs significantly from its current version. We consider Charles Dow to be the father of contemporary technical analysis, who laid its foundations between 1900 and 1902.

Dow focused on the use and analysis of the daily closing prices of eleven selected stocks, and co-founded the Dow Jones Financial News Service. His very important contribution in this area are the discussions in a series of articles in The Wall Street Journal, which we now consider to be the theoretical basis of technical analysis as we know it today. (Brock et al., 1992; Vanstone and Finnie, 2009; Zhu and Zhou, 2009).

Georg W. Bishop (1961) states that Charles Dow's overall contribution to the financial markets was much greater than the concept of technical theory itself. Vesela (2011) adds that the concept of Dow's theory itself was first formulated in the form of articles in the already mentioned periodical, The Wall Street Journal, which Charles H. Dow himself compiled between 1890 and 1902. The basis and starting point on which he based Dow's theory is that the stock market itself is, as a whole, a reliable and comprehensive measure of the economic situation within the economy and, using a comprehensive analysis of the entire market, it is possible to accurately identify the direction of major market trends in stock titles.

Technical analysis has existed since the days of organised markets in the form of an exchange, but was not adopted as a useful tool for predicting future price movements until the turn of the 1970s and 1980s. (Douglas, 2010) 
Based on the above, we can therefore state with certainty that trading as a separate activity, and even trading in derivatives, are not just an attribute today. It is clear that this area has undergone massive development since its inception; however, as we have said, it has its origins deep in human history.

\subsection{Current state of technical analysis research}

As a basis for the analysis of the current situation in this area, we used a study entitled, ' $A$ literature review of technical analysis on stock markets', published in November 2017 in the periodical, 'The Quarterly Review of Economics and Finance'. The authors of this study are Rodolfo Toribio Farias Nazarioa, Jessica Lima e Silvab, Vinicius Amorim Sobreiro, and Herbert Kimuraa. The reason for such a study was to consolidate the available knowledge on technical analysis. The main goal of this work was to summarise and systematise the significant research that had contributed to the development of this area by classifying and coding the identified published works. The contribution of this study in this area was to present an overview of the characteristics of the literature and potential knowledge gaps in the field of technical analysis. A significant number of the studies identified suggested that predicting returns in financial markets was a difficult and complex task (Teixeira and Oliveira, 2010; Zielonka, 2004). The very complexity of the market stems from its nonlinear and non-stationary properties. (Bisoi and Dash, 2014) The fact that the complexity of the market is influenced by a significant number factors, such as political events, market news, quarterly revenue reports, international influence and conflict trading, and the behaviour of individual participating economic operators, also contributes to this (Ticknor, 2013). Vanstone and Finnie (2009) drew attention to the field and the very existence of prediction methods such as fundamental and technical analysis in their work. Today, technical analysis or some of its procedures are used by many of today's traders; however, according to Park and Irwin (2009), it has not received sufficient support, especially at the academic level (Brock, et al., 1992; Menkhoff, 2010; Menkhoff and Taylor, 2007; Mitra, 2011; Zhu and Zhou, 2009), despite the fact that it can be easily identified in the financial markets (Schulmeister, 2009). To emphasise this, Lo, Mamaysky, and Wang (2000) focus on 'Fundamentals of Technical Analysis: Computational Algorithms, Statistical Inference, and Empirical Implementation'. We consider the following statement, which they published in this work, to be extremely important:

'It is argued that the difference between fundamental and technical analysis is a parallel to the difference between astronomy and astrology. In some circles, even technical analysis is considered a kind of voo-doo'.

Fundamental analysis focuses on the use of individual economic factors to estimate the intrinsic value of financial instruments, while technical analysis is based on historical data such as the prices and trading volume of the instruments analysed (Chavarnakul and Enke, 2009; Teixeira and Oliveira, 2010). We contend that fundamental analysis found its foundation in Graham's work, which can be found in his famous book, The Smart Investor. This publication recommends making individual purchases of stocks based on a set of rules based, in turn, on fundamental analysis. Several authors, such as Oppenheimer and Schlarbaum (1981) and Metghalchi, Chang, and Marcucci (2008), have evaluated these rules in their work. They concluded that, based on the rules, it was indeed possible to achieve higher returns than would be achieved with a buy-and-hold strategy. We understand technical analysis, as opposed to fundamental analysis, as a set of methods and tools that allow individual market participants to predict future returns on financial assets, based on a study of historical market characteristics such as prices and trading volume (Park and Irwin, 2007; Wei 
et al., 2011; Yamamoto, 2012; Zhu and Zhou, 2009). Recent studies have sought to combine different approaches, such as traditional trading rules, smart trading techniques, statistical models, neural networks, and genetic algorithms, with technical analysis. The result of these studies is the finding that it is possible to find such combinations of rules that will create a trading system that can predict the future direction of price development using historical data on prices and trading volumes. (Gorgulho et al., 2011) In this context, Fama and Blume (1966) sought to verify the performance of technical trading rules in the US stock market and identified a tendency that these filtering technical rules could not outperform the buy-and-sell strategy. Subsequently, Fama (1970) gathered his ideas and reflections on market performance and behaviour and presented his efficient market (EMH) hypothesis, which assumes that individual financial instrument prices reflect all available information. Other academics and experts continued to subject technical analysis techniques to various types of research, with the result that it could indeed be used as a tool to predict or indicate the future price movements of financial instruments. In other words, some of their results have outperformed the aforementioned buy-and-hold strategy. Of such publications, special emphasis is placed on Brock et al. (1992), Ratner and Leal (1999), Gunasekarage and Power (2001) and, especially, Lo et al. (2000), who added that technical analysis could add value to the investment process. Therefore, one of the identified research directions in this area focuses on market efficiency research. In this context, some works by Fernandez-Rodriguez, Gonzslez-Martel, and Sosvilla-Rivero (2000) and Chan et al. (2000) analyse whether the results of strategies based on technical trading rules are profitable. Further studies by authors such as Asness et al. (2013) recognise that there are technical strategies, such as price action strategies, which lead to a positive but risk-adjusted outcome. A survey by Parka and Irwin examined the profitability of technical analysis over the years. Their studies concluded that the work classified as initial studies found very low profitability of systems and techniques of technical analysis. However, the results of published work in the category of modern studies were much more uniform in their findings: out of 95 studies, 56 achieved positive results, while the rest achieved negative and mixed results from the use of technical analysis methods (Park and Irvin, 2007). Thus, in recent decades, studies published in major and prestigious academic journals can be evenly divided into those that support or reject the adequacy of the use of technical analysis as an investment tool (Allen and Karjalainen, 1999; Allen and Yang, 2004; Dempster and Jones, 2001; Ellis and Parbery, 2005; Gunasekarage and Power, 2001; Jegadeesh and Titman, 2001; Lo et al., 2000; Neely, 2003; Sullivan et al., 1999). In another work by Menkhoff and Taylor (2007), the authors sought to focus on the analysis of the use of technical analysis methods in foreign exchange markets. Their research concluded that the mere use of technical analysis could be explained by the very need for market players to have a tool for market assessment and for making individual business decisions. They also pointed out that technical analysis was undoubtedly part of the trading and foreign exchange markets themselves, and that it remained a 'passionate obsession' for traders and professionals in this field. Menkhoff and Taylor (2007) argued that technical analysis should be integrated directly at the microeconomic level from an academic point of view and that, from such a viewpoint, it should be seen as a tool for achieving above-standard returns.

\section{Methodology}

In their study entitled, 'A literature review of technical analysis on stock markets', published in November 2017 in The Quarterly Review of Economics and Finance, Rodolfo Toribio Farias Nazarioa, Jessica Lima e Silvab, Vinicius Amorim Sobreiro, and Herbert 
Kimuraa categorise and structure the research in the field of technical analysis over the last few dozen years (Table 1; according to Rodolfo Toríbio Farias Nazarioa et al., 2017).

Table 1: Used system of classification and coding

\begin{tabular}{|c|c|c|}
\hline Classification & Area & Categories \\
\hline \multirow{3}{*}{1} & \multirow{3}{*}{ Economy } & A - developed countries \\
\hline & & $\mathrm{B}-$ developing countries \\
\hline & & $\mathrm{C}$ - not applicable \\
\hline \multirow{4}{*}{2} & \multirow{4}{*}{ Methodology } & A - trading systems \\
\hline & & $\mathrm{B}-$ calculation techniques \\
\hline & & $\mathrm{C}-$ macroeconomic models \\
\hline & & $\mathrm{D}$ - graphic formations \\
\hline \multirow{3}{*}{3} & \multirow{3}{*}{ Application } & $\mathrm{A}-$ in the real market \\
\hline & & $\mathrm{B}$ - artificial markets \\
\hline & & $\mathrm{C}-$ not applicable \\
\hline \multirow[t]{2}{*}{4} & \multirow{2}{*}{$\begin{array}{c}\text { Transaction } \\
\text { costs }\end{array}$} & A - taken into account \\
\hline & & $\mathrm{B}-$ not taken into account \\
\hline \multirow{8}{*}{5} & \multirow{8}{*}{ Tools } & A - stochastic \\
\hline & & $\mathrm{B}$ - relative force index \\
\hline & & $\mathrm{C}$ - genetic algorithms \\
\hline & & D - evolutionary strengthening of learning \\
\hline & & $\mathrm{E}$ - statistical analysis \\
\hline & & $\mathrm{F}$ - moving averages \\
\hline & & $\mathrm{H}$ - neural networks \\
\hline & & $\mathrm{I}$ - other \\
\hline \multirow{3}{*}{6} & \multirow{3}{*}{ Results } & A - support technical analysis \\
\hline & & B - do not support technical analysis \\
\hline & & $\mathrm{C}$ - not applicable \\
\hline \multirow{3}{*}{7} & \multirow{3}{*}{ Risk } & $\mathrm{A}-$ taken into account \\
\hline & & $\mathrm{B}-$ not taken into account \\
\hline & & $\mathrm{C}$ - not applicable \\
\hline \multirow{7}{*}{8} & \multirow{7}{*}{$\begin{array}{c}\text { Risk } \\
\text { management }\end{array}$} & A - profitability taking into account risk management and transaction costs \\
\hline & & $\mathrm{B}$ - profitability taking into account only risk management \\
\hline & & $\mathrm{C}$ - profitability taking into account only transaction costs \\
\hline & & $\mathrm{D}$ - profitability taking into account neither risk management nor transaction costs \\
\hline & & E - not applicable \\
\hline & & $\mathrm{H}-$ neural networks \\
\hline & & I- others \\
\hline
\end{tabular}




\section{Results}

This study, considering the classification system, identified 85 significant publications in the field of technical analysis. However, the authors add that during the initial screening, many articles were excluded because they focused on pricing, liquidity modelling, and portfolio management, and therefore did not focus directly on technical analysis research and its methods in the process of predicting the price movements of financial instruments.

Individual studies that support technical analysis with their findings have contributed their results to research in this area, and many of them have found new models of technical trading, e.g. with artificial intelligence, fuzzy logic, and more. It is crucial to note that contributions that do not support technical analysis do not support it on the grounds that they have achieved negative profitability in their results and thus found that the techniques used have weak predictive power. Here, it must be realised that the end result of a trading system based on technical analysis techniques cannot tell us exactly whether a given technique is functional and whether it can predict the future price development of financial instruments. The end result of a trading system is the result of a combination of all trading rules. Achieving a loss from the trading system does not always mean a mistake in the prediction technique, it is often a mistake of poorly set risk management. Not only did the authors classify the studies according to profitability, but they also analysed whether the contributions focused on technical analysis considered risk issues, because profitability can be affected by many types of factors, such as transaction costs and risk. Due to this issue, Category 7 - Risk, and Category 8 - Risk adjustment are added in the overall structuring of the articles. In Category 8 , the authors evaluate whether the profitability of the strategy is adjusted for risk, transaction costs, or both. Surprisingly, less than $44 \%$ of the identified significant studies evaluated adjusted profitability using some type of risk indicator. For the documents that considered risk adjustment, $62 \%$ also considered transaction costs.

Table 2: The resulting structure of the analyzed publications according to Table 1

\begin{tabular}{cccccccccc}
\hline \multicolumn{10}{c}{ Classifications } \\
& & $\boldsymbol{1}$ & $\mathbf{1}$ & $\mathbf{3}$ & $\mathbf{4}$ & $\mathbf{5}$ & $\boldsymbol{6}$ & $\mathbf{7}$ & $\boldsymbol{8}$ \\
& $\boldsymbol{A}$ & 53 & 58 & 80 & 43 & 9 & 79 & 37 & 23 \\
& $\boldsymbol{B}$ & 23 & 31 & 9 & 43 & 10 & 6 & 41 & 14 \\
& $\boldsymbol{C}$ & 11 & 2 & 1 & - & 15 & 4 & 7 & 13 \\
Categories & $\boldsymbol{D}$ & - & 8 & - & - & 4 & - & - & 26 \\
& $\boldsymbol{E}$ & - & - & - & - & 30 & - & - & 9 \\
& $\boldsymbol{F}$ & - & - & - & - & 44 & - & - & - \\
& $\boldsymbol{G}$ & - & - & - & - & 10 & - & - & - \\
& $\boldsymbol{H}$ & - & - & - & - & 15 & - & - & - \\
& $\boldsymbol{I}$ & - & - & - & - & 33 & - & - & - \\
\hline
\end{tabular}

Source: Rodolfo Toribio Farias Nazarioa et al. (2017)

The following findings are the result of the literature search. The authors identified 85 significant studies in the field of technical analysis research, which they subsequently analysed and divided into eight areas and other subcategories (see Table 1) according to their focus. Based on a study of these publications, we can say with certainty that technical analysis and its various methods are undoubtedly applied on the financial market. The reason for using 
them even without clear academic support is the need to have a tool that will help traders and other market participants in business- and other decision-making.

\section{Discussion}

An important finding is that the research in this area is inconsistent, while each of the authors focused on a different aspect of technical analysis. We consider this to be a natural phenomenon; however, in some cases, the authors generalise the results, and their effects apply to the whole area of technical analysis. As we have already mentioned, it is not possible to say that any method of technical analysis is functional or, conversely, non-functional, based on the outcome of the business process. (Douglas, 2010; Vesela, 2007) Here, it should be noted that the final result of business activity is the result of the whole complex business system, where prediction methods (in our case, prediction methods from the field of technical analysis) play only a certain partial role. Therefore, we consider it more valuable to quantify the success rate of the prediction of a given instrument, because even a low predictive ability (30\% success rate of future price developments) can yield above-standard results. We can also state that a fundamental problem in the work of assessing technical analysis, its predictive ability and suitability for use in a given market, is the inconsistency in the assessment of transaction costs. We consider this to be a particularly serious finding, given that transaction costs and their incurrence are directly conditioned by business activity and therefore cannot be avoided by a trader or an investor. It should also be borne in mind that transaction costs directly affect the overall trading result and therefore their misjudgement can distort and devalue research. This distortion can be manifested mainly in the case of marginal trading results, where not including transaction costs in the total result may cause an otherwise negative trading result to be considered positive. On the other hand, we also accept the fact that we cannot consider transaction costs to be uniform. Each entity has freedom in the choice of trading method and in the choice of an intermediary. (Musilek, 2011; Kohout, 1998)

Each method of execution of a transaction has a different cost, and therefore, noninclusion of transaction costs may be justified in certain cases. Based on this finding, we have concluded for the further needs of the trading system design that the optimal way to assess the success of the system will be the method that excludes transaction costs. Thus, we will achieve comprehensive results from the system assessed in this way, which will be based only on the properties of the techniques used and parts of the trading system. It is also very interesting to find that technical analysis is used in both emerging and developed markets. This fact is not related to the possible suitability of using these techniques, but to the fact that traders are trying to take advantage of and seek trading opportunities to make financial profits. (Turek, 2011) Thus, the presence of technical analysis itself, regardless of the type of market, is attributed to the traders themselves and their efforts to generate profits. Of course, different types of markets provide different types of opportunities; however, traders themselves and their market activity require the use of a tool to predict future price developments and a tool to help them in the business decision-making process that technical analysis is. Another very important and interesting finding is the fact that, based on the analysis of the results of the identified studies, the number of studies that support technical analysis and whose results prove the profitability of individual systems based on technical rules is significant. This fact can be caused by two basic factors. The first factor is that technical analysis has become very widespread and well-known, and thus the number of traders who use it has increased. This fact positively affects the profitability of individual methods of technical analysis in such a way that the more traders use a particular method, the more orders will tend to trade in a 
particular direction at a particular price. Moreover, since we know that the market is a place of demand and supply for a particular instrument, an imbalance between supply and demand will disrupt the market price and change its direction. The second factor that may cause the growing trend of positive results in this area is the development in technology, computer technology, and software, which is reflected in the other trading rules that make up individual trading systems. For these findings, research in this area is insufficient; existing research is sporadic and does not focus on the issue of technical analysis comprehensively.

\section{Conclusion}

The aim of our contribution was to examine, in detail, the basics and current research in the field of technical analysis, as this field is full of ambiguities and myths. In the first chapter of our paper, we elaborated on the historical development of trading, financial derivatives, and areas focused on trade itself. We also continued to process the current state of the issue with a focus on scientific publications. In the second chapter, based on previous research, we processed the categorisation of individual publications in the area. And last but not least, we interpreted the results of the research and described their limits in detail. We consider the goal of the study to have been met, and believe that our contribution will be valuable to research in this area.

Author contributions: All authors listed have made a substantial, direct and intellectual contribution to the work, and approved it for publication.

Funding: This research received no external funding.

Data Availability Statement: The data presented in this study are available on request from the corresponding author. The data are not publicly available due to own empirical research of corresponding author.

Conflicts of Interest: The authors declare no conflict of interest.

\section{References}

Allen, F., \& Karjalainen, R. (1999). Using genetic algorithms to find technical trading rules, Journal of Financial Economics, 64(3-4), 245-271.

Allen, D., \& Yang, W. (2004). Do UK stock prices deviate from fundamentals?, Mathematics and Computers in Simulation, 64(3-4), 373-383.

Asness, C.S., Moskowitz, T.J., \& Pedersen, L.H. (2013). Value and momentum everywhere, The Journal of Finance, 68(3), 929-985.

Bascin, V. (2007). The beginnings of the public stock market: The first signs of stock trading in the Middle Ages ( $1^{\text {st }}$ eddition). http://investor.hnonline.sk/c1-24939980-pociatky- verejneho-trhu-s-akciami

Bisoi, R., \& Dash, P. (2014). A hybrid evolutionary dynamic neural network for stock market trend analysis and prediction using unscented Kalman filter, Applied Soft Computing, 19(1), 41-56.

Brock, W., Lakonishok, J., \& LeBaron, B. (1992). Simple technical trading rules and the stochastic properties of stock returns, The Journal of Finance, 47(5), 1731-1764.

Cowles, A. (1933). Can stock market forecasters forecast?, Econometrica, 1(3), 309-324.

Dempster, M.A.H., \& Jones, C.M. (2001). A real-time adaptive trading system using genetic programming, Quantitative Finance, 1(4), 397-413.

Don. M Chance (1998). Essay in Derivates. Frank J. Fabbozi Associates New Hope, Pennsylvania. ISBN: 1883249-46-5

Douglas, M. (2010). Trading in the zone - The secret of success on the stock markets, IMPOSSIBLE s.r.o., ISBN 978-80-254-7066-4. 
Ellis, C.A., \& Parbery, S.A. (2005). Is smarter better? A comparison of adaptive, and simple moving average trading strategies, Research in International Business and Finance, 19(3), 399-411.

Fama, E.F. \& Blume, M.E. (1966). Filter rules and stock-market trading, Journal of Business, 39(1), $226-241$.

Fama, E.F. (1970). Efficient capital markets: A review of theory and empirical work, The Journal of Finance, 25(2), 383-417.

Fernandez-Rodriguez, F., Gonzalez-Martel, C., \& Sosvilla-Rivero, S. (2000). On the profitability of technical trading rules based on artificial neural networks: Evidence from the Madrid stock market, Economics Letters, 69(1), 89-94.

Gorgulho, A., Neves, R., \& Horta, N. (2011). Applying a GA kernel on optimizing technical analysis rules for stock picking and portfolio composition, Expert Systems with Applications, 38(11), 14072-14085.

Gunasekarage, A., \& Power, D.M. (2001). The profitability of moving average trading rules in South Asian stock markets, Emerging Markets Review, 2(1), 17-33.

Hrvolova, B., Pogorielov, R., \& Polednakova, A. (2001). Analysis of financial markets, Bratislava: Sprint vfra, 2001. 373 s. ISBN 80-88848-86-5.

Chan, K., Hameed, A., \& Tong, W. (2000). Profitability of momentum strategies in the international equity markets, The Journal of Financial and Quantitative Analysis, 35(2), 153-172.

Chavarnakul, T., \& Enke, D. (2009). A hybrid stock trading system for intelligent technical analysis-based equivolume charting, Neurocomputing, 72(16-18), 3517-3528.

Jegadeesh, N., \& Titman, S. (2001). Profitability of momentum strategies: An evaluation of alternative explanations, The Journal of Finance, 56(2), 699-720.

Kohout, P. (1998). Money, Revenues and Risks - Investment Strategy Handbook, Ekopress, Prague 1, ISBN 8086119-06-8.

Lo, A.W., Mamaysky, H., \& Wang, J. (2000). Foundations of technical analysis: Computational algorithms, statistical inference, and empirical implementation, The Journal of Finance, 55(4), 1705-1770.

Menkhoff, L., \& Taylor, M.P. (2007). The obstinate passion of foreign exchange professionals: Technical analysis, Journal of Economic Literature, 45(4), 936-972.

Menkhoff. L. (2010). The use of technical analysis by fund managers: International evidence, Journal of Banking \& Finance, 34(11), 2573-2586.

Metghalchi, M., Chang, Y.-H., \& Marcucci, J. (2008). Is the Swedish stock market efficient? Evidence from some simple trading rules, International Review of Financial Analysis, 17(3), 475-490.

Mitra, S.K. (2011). How rewarding is technical analysis in the Indian stock market?, Qantitative Finance, 11(2), 287-297.

Musilek, P. (2011). Stock markets. 2nd, updated and expanded edition, In: Prahgue, Ekopress, ISBN 9788086929705.

Neely, C.J. (2003). Risk-adjusted, ex ante, optimal technical trading rules in equity markets, International Review of Economics \& Finance, 12(1), 69-87.

Northcott, A. (2009). The complete guide to using candlestick charting: How to earn high rates of return-safely, Atlantic Publishing Group Inc., Ocala, No. 1601382944.

Oppenheimer, H.R., \& Schlarbaum, G.G. (1981). Investing with Ben Graham: An Ex Ante test of the efficient markets hypothesis, Journal of Financial and Quantitative Analysis, 16(3), 341-360.

Park, C.-H., \& Irwin, S.H. (2007). What do we know about the profitability of technical analysis?, Journal of Economic Surveys, 21(4) 786-826.

Park, C.-H., Irwin, S.H. (2009). A reality check on technical trading rule profits in the U.S. futures markets, Journal of Futures Markets, 30(7), 633-659.

Pavlat, V. (2003). Stock exchanges, 1st ed. University of Finance and Administration, ISBN 9788023902303.

Ratner, M., \& Leal, R.P. (1999). Tests of technical trading strategies in the emerging equity markets of Latin America and Asia, Journal of Banking \& Finance, 23(12), 1887-1905.

Rodriguez-Gonzalez, A., Garcia-Crespo, A., Colomo-Palacios, R., Iglesias, F.G., \& Gomez-Berbis, J.M. (2011). CAST: Using neural networks to improve trading systems based on technical analysis by means of the RSI financial indicator, Expert Systems with Applications, 38(9), 11489-11500. 
Schulmeister, S. (2009). Profitability of technical stock trading: Has it moved from daily to intraday data?, Review of Financial Economics, 18(4), 190-201.

Siegel, J.J. (2011). Investment in shares long-distance running, GRADA Publishing, a.s., ISBN 978-80-2473860-4

Stupavsky, M. (2007). It started with grain and ended with the weather. http://www.penize.cz/19026-zacalo-toobilim-a-zatim-skoncilopocasim

Sullivan, R., Timmermann, A., \& White, H. (1999). Data-snooping, technical trading rule performance, and the bootstrap, The Journal of Finance, 54(5), 1647-1691.

Teixeira, L.A., \& Oliveira, A.L.I.D. (2010). A method for automatic stock trading combining technical analysis and nearest neighbour classification, Expert Systems with Applications, 37(10), 6885-6890.

Ticknor, J.L. (2013). A Bayesian regularized artificial neural network for stock market forecasting, Expert Systems with Applications, 40(14), 5501-5506.

Turek, L., (2011). Technical analysis manual 1ed., CZECHWEALTH, s.r.o.

Vanstone, B., \& Finnie, G. (2009). An empirical methodology for developing stockmarket trading systems using artificial neural networks, Expert Systems with Applications, 36(3), 6668-6680.

Vesela, J., (2007). Investing in capital markets 2. update. ed., Wolters Kluwer, ISBN 978-80-7357-647-9.

Wei, L.-Y., Chen, T.-L., \& Ho, T.-H. (2011). A hybrid model based on adaptive-network-based fuzzy inference system to forecast Taiwan stock market, Expert Systems with Applications, 38(11), 13625-13631.

Yamamoto, R. (2012). Intraday technical analysis of individual stocks on the Tokyo Stock Exchange, Journal of Banking \& Finance, 36(11), 3033-3047.

Zhu, Y., \& Zhou, G. (2009). Technical analysis: An asset allocation perspective on the use of moving averages, Journal of Financial Economics, 92(3), 519-544.

Zielonka. P. (2004). Technical analysis as the representation of typical cognitive biases, International Review of Financial Analysis, 13(2), 217-225. 